\title{
Clandestine induced abortion: prevalence, incidence and risk factors among women in a Latin American country
}

\author{
Antonio Bernabé-Ortiz MD, Peter J. White PhD, Cesar P. Carcamo MD PhD, James P. Hughes PhD, \\ Marco A. Gonzales, Patricia J. Garcia MD MPH, Geoff P. Garnett PhD, King K. Holmes MD PhD
}

$\infty \quad$ See related commentary by Cook, page 272

\section{ABSTRACT}

Background: Clandestine induced abortions are a public health problem in many developing countries where access to abortion services is legally restricted. We estimated the prevalence and incidence of, and risk factors for, clandestine induced abortions in a Latin American country.

Methods: We conducted a large population-based survey of women aged 18-29 years in 20 cities in Peru. We asked questions about their history of spontaneous and induced abortions, using techniques to encourage disclosure.

Results: Of 8242 eligible women, 7992 (97.0\%) agreed to participate. The prevalence of reported induced abortions was $11.6 \%$ (95\% confidence interval [CI] 10.9\%-12.4\%) among the 7962 women who participated in the survey. It was $13.6 \%$ (95\% Cl 12.8\%-14.5\%) among the 6559 women who reported having been sexually active. The annual incidence of induced abortion was 3.1\% (95\% Cl 2.9\%-3.3\%) among the women who had ever been sexually active. In the multivariable analysis, risk factors for induced abortion were higher age at the time of the survey (odds ratio [OR] $1.11,95 \% \mathrm{Cl} 1.07-1.15)$, lower age at first sexual intercourse (OR 0.87, 95\% Cl 0.84-0.91), geographic region (highlands: OR 1.56, 95\% Cl 1.23-1.97; jungle: OR 1.81, $95 \% \mathrm{Cl} 1.41-2.31$ [v. coastal region]), having children (OR $0.82,95 \% \mathrm{Cl} 0.68-0.98)$, having more than 1 sexual partner in lifetime ( 2 partners: OR $1.61,95 \% \mathrm{Cl} 1.23-2.09$; $\geq 3$ partners: OR $2.79,95 \% \mathrm{Cl} 2.12-3.67)$, and having 1 or more sexual partners in the year before the survey (1 partner: OR 1.36, 95\% Cl 1.01-1.72; $\geq 2$ partners: OR $1.54,95 \% \mathrm{Cl} 1.14$ 2.02). Overall, $49.0 \%(95 \% \mathrm{Cl} 47.6 \%-50.3 \%)$ of the women who reported being currently sexually active were not using contraception.

Interpretation: The incidence of clandestine, potentially unsafe induced abortion in Peru is as high as or higher than the rates in many countries where induced abortion is legal and safe. The provision of contraception and safersex education to those who require it needs to be greatly improved and could potentially reduce the rate of induced abortion.

Une version française de ce résumé est disponible à l'adresse www.cmaj.ca/cgi/content/full/180/3/298/DC1

CMAJ 2009;180(3):298-304
$\mathrm{I}$ $\mathrm{n}$ most developing countries, induced abortion is legal only if the pregnancy threatens the health or life of the mother. Many women, therefore, seek clandestine abortions, which are too often unsafe and place the woman at risk of complications and death.

Forty percent of women live in countries where abortion is legally restricted. ${ }^{2}$ In 2003, an estimated 55\% of induced abortions in developing countries were unsafe, and $97 \%$ of all unsafe abortions were in developing countries. ${ }^{3}$ Induced abortion is highly restricted in most countries in Latin America and the Caribbean. ${ }^{1}$ According to the World Health Organization (WHO), the region of Latin America and the Caribbean has the same estimated incidence of clandestine induced abortions as Africa (3\% per year among women aged 15-44 years). ${ }^{4}$ It also has the highest proportion of maternal death from unsafe abortion (12\%). Women who have complications from clandestine abortions may not seek medical help for fear of being reported to legal authorities by health care workers. ${ }^{6.7}$

Elimination of unsafe abortions is a key component of sexual and reproductive health care. ${ }^{8}$ There is a public health need to determine more accurately the burden of, and risk factors for, clandestine induced abortion in different countries. Because of data limitations, the WHO reports only regional estimates. ${ }^{4}$ The lack of official records and underreporting by those involved make this task difficult, requiring that estimates calculated by different methods be compared.

Rates of clandestine induced abortion are estimated with the use of either direct methods, such as population-based surveys and surveys of providers of illegal abortions, or indirect methods, such as the application of multipliers to recorded rates of hospital admission or death attributed to induced abortions. ${ }^{49}$

We performed a large, representative, population-based survey to determine the prevalence and incidence of, and risk factors for, induced abortion in an urban population of a Latin American country where access to abortion services is legally restricted.

From the Universidad Peruana Cayetano Heredia (Bernabé-Ortiz, Carcamo Gonzales, Garcia), Lima, Peru; MRC Centre for Outbreak Analysis and Modelling, Department of Infectious Disease Epidemiology, Faculty of Medicine (White, Garnett), Imperial College London, London, UK; and the Center for AIDS and STD (Hughes, Holmes) and the Department of Global Health and Medicine (Holmes), University of Washington, Seattle, USA 


\section{Methods}

\section{Study design and participants}

We designed a population-based survey to be conducted in 20 cities in Peru between September and December 2005 with the use of handheld computers. We selected a random sample of women aged 18-29 years, drawn using a standard probabilistic 3-step procedure and data from the 1999 Peruvian census. The first step involved the random selection of 108 clusters of individual or groups of contiguous residential blocks for each participating city; each block comprised 40 households on average. Second, a new census of households in the selected clusters was conducted by trained interviewers to collect information about location and type of housing, household size, number of people aged 18-29 years, and length of time of residence in the city. We then selected a random sample of 10 households with eligible members from each cluster. Eligible participants were female, aged 18-29 years and had been living in the city for at least 6 months. Finally, within each household we chose 1 eligible individual, based on most recent birthday.

Selected participants were interviewed by specially trained nurses and midwives who confirmed eligibility, obtained informed consent and administered the questionnaire. If eligibility could not be confirmed, another eligible person in the same household with the next most recent birthday was asked to participate. If there was no other eligible woman willing to participate, none was recruited from that household.

At least 300 women were recruited from each city. Not all clusters of residential blocks were required.

\section{Questionnaire}

The questionnaire was administered in Spanish by nurses and midwives who completed an extensive 12-day training program. It had 2 parts, both administered in the absence of a third party. The first part of the questionnaire was administered face to face. With it, the nurse or midwife collected data on demographic characteristics, prior pregnancies and use of contraception. The second part was self-administered, out of sight of the interviewer to ensure confidentiality. Both parts of the questionnaire asked the same questions about the number of abortions and number of spontaneous abortions in the first 3 months of pregnancy in the woman's lifetime. The combination of questionnaire methods has been found to increase reporting. ${ }^{10-12}$

The questions in Spanish, and an English translation, are available in Appendix 1 (available at www.cmaj.ca/cgi /content/full/180/3/298/DC2).

\section{Definitions}

In Peru, the term "abortion" refers to "pregnancy loss," "miscarriage" and "induced abortion." Because induced abortion is a highly sensitive topic, we used 2 questions that our research group previously pilot-tested in a group of 200 women from the general public. The questions were: "Have you ever had a pregnancy that ended in an abortion in the first 3 months of pregnancy? If so, how many?" and "Did you ever have an abortion that was spontaneous in the first 3 months of pregnancy? If so, how many?"
The number of induced abortions was calculated from the difference between the number of total abortions and of spontaneous abortions.

\section{Ethical issues}

Institutional review boards at the Universidad Peruana Cayetano Heredia, Lima (Peru), the US Naval Medical Research Center in Lima and the University of Washington, Seattle (United States) approved the study design. Informed consent was obtained from each participant.

\section{Statistical analysis}

Data were transferred from the handheld computers to a desktop computer in each city and then sent by email to the Database Management Center in Lima, where they were merged for analysis.

We used logistic regression analysis to estimate odds ratios (ORs) with 95\% confidence intervals (CIs) for associations between the participants' characteristics at the time of the interview and their reported history of induced abortion. The analysis was adjusted for sample strata, primary sampling units and population weights. Variables that we found to be significant $(p<0.10)$ in the bivariable analysis were entered into a multivariable logistic regression model using a forward conditional method (likelihood ratio test). We used kappa analysis to evaluate agreement between answers to corresponding questions in the face-to-face and self-administered parts of the questionnaire.

We calculated the incidence of abortion by dividing the number of abortions by the number of person-years at risk. When considering all women aged 15-29 years, we calculated the number of person-years at risk by subtracting 15 years from the age at the interview. When considering women aged 15-29 years who had ever been sexually active, we calculated the number of person-years at risk by subtracting the age at first sexual intercourse from the age at the interview.

\section{Results}

Of 8242 eligible women, $7992(97.0 \%)$ agreed to participate. We excluded 30 because some of their responses were inconsistent (e.g., between age at interview and age at first sexual intercourse, or between number of sexual partners in lifetime and in the 12 months before the interview). Of the remaining 7962 women, 1697 (21.3\%, 95\% CI 21.0\%-22.8\%) reported 2123 abortions (spontaneous and induced), for a rate of 1.25 abortions per person. Induced abortions were reported by 923 of the 7962 women $(11.6 \%, 95 \%$ CI $10.9 \%-12.4 \%)$.

Of the 6559 women who reported ever having been sexually active, 892 (13.6\%, 95\% CI 12.8\%-14.5\%) had had an induced abortion. Of those aged 18 years with a history of sexual activity (55\% of all participants aged 18$), 7.5 \%(95 \%$ CI 5.2\%-10.4\%) reported having had an induced abortion.

Of the 4740 women who reported ever having been pregnant, $892(18.8 \%, 95 \%$ CI 17.7\%-19.9\%) reported having had a total of 1127 induced abortions; 724 reported one, 121 reported two, and 47 reported three or more induced abortions. Of all of the recognized pregnancies (pregnancies that 
the women were aware of), $2123(24.5 \%, 95 \%$ CI $23.6 \%-$ $25.4 \%$ ) were reported to have ended in abortion; 996 of these $(11.5 \%, 95 \%$ CI $10.8 \%-12.2 \%)$ were spontaneous, and 1127 $(13.0 \%, 95 \%$ CI $12.3 \%-13.8 \%)$ were induced.

There was $90.6 \%$ agreement $(\mathrm{kappa}=0.72,95 \%$ CI 0.70 0.74 ) between the responses in the face-to-face interview and self-administered questionnaire for reporting ever having had a spontaneous or induced abortion. There was 91.2\% agreement $(\mathrm{kappa}=0.63,95 \%$ CI $0.60-0.65)$ between the responses for reporting spontaneous abortion, and $91.2 \%$ agreement (kappa $=0.47,95 \%$ CI 0.45-0.50) for reporting induced abortion. Among the women who reported having had any induced abortions in both the face-to-face interview and the self-administered questionnaire, there was $83.2 \%$ agreement (kappa $=0.50,95 \%$ CI 0.41-0.58) regarding the number of induced abortions reported.

The annual incidence of all reported abortions (spontaneous and induced) among women aged 15-29 years was $5.9 \%$ (95\% CI 5.6\%-6.1\%) among those who reported having ever been sexually active. It was 3.7\% (95\% CI 3.6\%$3.9 \%$ ) among all of the participants. The annual incidence of reported induced abortion was 3.1\% (95\% CI 2.9\%-3.3\%) among the women who reported having been sexually active and $2.0 \%$ (95\% CI $1.9 \%-2.1 \%$ ) among all of the participants. The rates varied by geographic region, with women in cities in the jungle region having the highest incidence (Table 1).

Factors associated with induced abortion among the women who reported having been sexually active are shown in Table 2. In the multivariable analysis, adjusted for sample strata, primary sampling units and population weights, we found that ever having had an induced abortion was associated with higher (v. lower) age at interview $(p<0.001)$, geographic region $(p<0.001)$, lower $(v$. higher) age at first sexual intercourse $(p<0.001)$, having children $(p<0.03)$, having had more than 1 sexual partner in lifetime $(p<0.001)$ and having 1 or more sexual partners in the year before the survey $(p<0.005)$ (Figure 1). We found that education level and income had no effect.

Of 5222 women who reported being currently sexually active, $2557(49.0 \%$, 95\% CI $47.6 \%-50.3 \%)$ were not using contraception.

\section{Interpretation}

Our large, representative, population-based survey, which had a very high participation rate, provides an estimate of the prevalence and incidence of, and risk factors for, induced abortion among women aged 18-29 years living in urban centres across Peru. As is typical of Latin American countries, Peru does not have comprehensive official statistics on abortion because the service is offered only if the mother's life or health are threatened. Of note, among the 18-year-old participants, the youngest group in the study, $7.5 \%$ of those who reported ever having been sexually active had had an induced abortion. The prevalence of induced abortion among the participants who reported ever having been sexually active $(13.6 \%)$ was similar to the prevalence of $15.4 \%$ among sexually experienced women of the same age (Dr. Catherine $\mathrm{H}$. Mercer, Centre for Sexual Health and HIV Research, University College London, London, UK: personal communication, 2008) in a population-based survey in Britain, ${ }^{13}$ where induced abortion is legal.

At $2.0 \%$ per year, the estimated incidence of reported induced abortion in Peru among all women aged 15-29 in our study is close to Britain's annual rate of $2.56 \%$ (95\% CI $2.51 \%-2.61 \%)$ in the same age group. ${ }^{14,15}$ The estimated incidence in the United States is $2 \%-3 \%$ per year. ${ }^{16}$ The rates in Britain and the United States are based on clinical records, whereas our estimate for Peru is based on self-reported data. With about $60 \%$ of induced abortions typically reported by survey respondents in countries where induced abortion is legal, ${ }^{10,17}$ we would expect our estimate to be no greater than $60 \%$ of the true value, despite our having taken steps to encourage disclosure, given the restricted illegality of induced abortion in Peru. The true annual incidence would be at least 3.3\%.

In Peru's Demographic and Health Survey, ${ }^{18}$ the prevalence of reported miscarriage, abortion or stillbirth (figures specifically for induced abortion were not available) among urban women aged 18-29 years was $8.6 \%$ (95\% CI $7.8 \%-$ $9.4 \%$ ). In our study, the prevalence of abortion (spontaneous and induced) was $21.9 \%$, which suggests lower rates of underreporting in our study. Overall, $11.5 \%$ of the recognized pregnancies in our study were reported to have ended in

Table 1: Annual incidence of all abortions (spontaneous and induced) and of induced abortions among women with a history of sexual activity and among all women in the study from age 15 to 29 years, * by region

\begin{tabular}{|c|c|c|c|c|}
\hline \multirow[b]{3}{*}{ Region } & \multicolumn{4}{|c|}{ Annual incidence $(95 \% \mathrm{Cl}), \%$} \\
\hline & \multicolumn{2}{|c|}{ All abortions } & \multicolumn{2}{|c|}{ Induced abortions } \\
\hline & $\begin{array}{l}\text { Women with history } \\
\text { of sexual activity }\end{array}$ & All women & $\begin{array}{l}\text { Women with history } \\
\text { of sexual activity }\end{array}$ & All women \\
\hline All & $5.9(5.6-6.1)$ & $3.7(3.6-3.9)$ & $3.1(2.9-3.3)$ & $2.0(1.9-2.1)$ \\
\hline Coastal & $5.3(4.9-5.6)$ & $3.4(3.1-3.6)$ & $2.4(2.2-2.7)$ & $1.5(1.4-1.7)$ \\
\hline Highlands & $6.0(5.6-6.3)$ & $3.6(3.3-3.8)$ & $3.1(2.8-3.4)$ & $1.9(1.7-2.0)$ \\
\hline Jungle & $6.7(6.2-7.3)$ & $4.9(4.5-5.3)$ & $4.4(3.9-4.8)$ & $3.2(2.9-3.5)$ \\
\hline
\end{tabular}


Table 2: Characteristics of 6266 women in Peru with a history of sexual activity who did and did not report ever having had an induced abortion*

\begin{tabular}{|c|c|c|c|}
\hline \multirow[b]{2}{*}{ Characteristic } & \multicolumn{2}{|c|}{ Had induced abortion; no. (\%) of woment } & \multirow[b]{2}{*}{ Crude OR $(95 \% \mathrm{Cl})$} \\
\hline & $\begin{array}{c}\text { No } \\
n=5374\end{array}$ & $\begin{array}{c}\text { Yes } \\
n=892\end{array}$ & \\
\hline Age, year, mean (SD) & $23.6(3.4)$ & $24.4(3.3)$ & $1.08(1.06-1.10) \S$ \\
\hline \multicolumn{4}{|l|}{ Region } \\
\hline Coastal & $2263(88.3)$ & $301(11.7)$ & 1.00 (ref) \\
\hline Highlands & $2078(86.7)$ & $319(13.3)$ & $1.15(0.98-1.37)$ \\
\hline Jungle & $1033(79.2)$ & $272(20.8)$ & $1.98(1.65-2.37)$ \\
\hline \multicolumn{4}{|l|}{ Education level } \\
\hline Low (< 12 years) & $2960(85.9)$ & $487(14.1)$ & 1.00 (ref) \\
\hline High ( $\geq 12$ years) & $2283(85.5)$ & $386(14.5)$ & $1.03(0.89-1.19)$ \\
\hline \multicolumn{4}{|l|}{ Religion } \\
\hline Other & $963(83.7)$ & $187(16.3)$ & 1.00 (ref) \\
\hline Catholic & $4397(86.2)$ & $705(13.8)$ & $0.83(0.69-0.98)$ \\
\hline \multicolumn{4}{|l|}{ Marital status } \\
\hline Unmarried & $4451(85.5)$ & $753(14.5)$ & 1.00 (ref) \\
\hline Married & $914(86.8)$ & $139(13.2)$ & $0.90(0.74-1.09)$ \\
\hline \multicolumn{4}{|l|}{ Employment } \\
\hline Unemployed & $4284(86.8)$ & $654(13.2)$ & 1.00 (ref) \\
\hline Employed & $1085(82.1)$ & $236(17.9)$ & $1.43(1.21-1.68)$ \\
\hline \multicolumn{4}{|l|}{ Income per month, soles $\ddagger$} \\
\hline Low $(\leq 500)$ & $4925(86.0)$ & $799(14.0)$ & 1.00 (ref) \\
\hline High $(>500)$ & $389(84.6)$ & $71(15.4)$ & $1.13(0.86-1.46)$ \\
\hline $\begin{array}{l}\text { Age at first sexual intercourse, } \\
\text { year, mean (SD) }\end{array}$ & $18.3(2.9)$ & $17.2(2.6)$ & $0.86(0.84-0.89)$ ा \\
\hline \multicolumn{4}{|l|}{ Number of children } \\
\hline 0 & $2128(86.7)$ & $326(13.3)$ & 1.00 (ref) \\
\hline$\geq 1$ & $3185(85.2)$ & $553(14.8)$ & $1.13(0.98-1.31)$ \\
\hline \multicolumn{4}{|l|}{ Use of contraception } \\
\hline No & $2882(86.5)$ & $448(13.5)$ & 1.00 (ref) \\
\hline Yes & $2334(84.4)$ & $430(15.6)$ & $1.19(1.03-1.37)$ \\
\hline \multicolumn{4}{|c|}{ Number of sexual partners in lifetime } \\
\hline 1 & $3032(91.6)$ & 277 (8.4) & 1.00 (ref) \\
\hline 2 & $1301(85.8)$ & $216(14.2)$ & $1.82(1.50-2.20)$ \\
\hline$\geq 3$ & $879(71.8)$ & $346(28.2)$ & $4.31(3.62-5.13)$ \\
\hline \multicolumn{4}{|c|}{ Number of sexual partners in last year } \\
\hline 0 & $1377(90.7)$ & $141 \quad(9.3)$ & 1.00 (ref) \\
\hline 1 & $3347(86.0)$ & $546(14.0)$ & $1.59(1.31-1.94)$ \\
\hline$\geq 2$ & $598(75.4)$ & $195(24.6)$ & $3.18(2.51-4.04)$ \\
\hline \multicolumn{4}{|c|}{$\begin{array}{l}\text { Received money, gifts or favours for sex } \\
\text { from } 1 \text { or more of the last } 3 \text { sexual } \\
\text { partners }\end{array}$} \\
\hline No & $5187(86.0)$ & $843(14.0)$ & 1.00 (ref) \\
\hline Yes & $157(78.1)$ & $44(21.9)$ & $1.72(1.22-2.43)$ \\
\hline
\end{tabular}

Note: $\mathrm{Cl}=$ confidence interval, $\mathrm{OR}=$ odds ratio, ref = reference group, $\mathrm{SD}=$ standard deviation.

*A total of 6559 women reported having ever been sexually active; 6266 are included in this table because they answered all of the questions.

tUnless stated otherwise. Percentages are calculated from row totals.

¥One soles = about US\$170.

§Per year.

ПPer year of delay of first sexual intercourse. 
spontaneous abortion; however, the true rate of spontaneous abortion in recognized pregnancies has been estimated to be $9 \%$ among women under 30 years old.$^{19}$ It could be that some of the women in our study reported an induced abortion as spontaneous.

Given the difficulties in estimating rates of clandestine induced abortion, it is important to compare estimates derived from different approaches. Ferrando ${ }^{20}$ estimated Peru's incidence of induced abortion to be $5.2 \%$ per year among women aged 15-49 years. To compare this figure with our estimate, we applied an adjustment factor of 1.17 to Ferrando's value. (To obtain this factor, we multiplied Ferrando's estimate by the proportion of induced abortions in Latin America experienced by women aged 15-29 years [i.e., 70\% $\%^{4,21}$ and 60\% ${ }^{22}$ ] and divided it by the proportion of the Peruvian female population of 15-49 years old that is aged 15-29 years [i.e., $60 \%$ ].) We obtained an adjusted estimate of $6.1 \%$ per year among all women aged 15-29 years, which is higher than our estimate of 3.3\%. Ferrando's incidence was obtained by applying an estimated multiplier to recorded rates of hospital admission owing to abortion-related complications; the value of 7 used in that study was at the upper end of the typical range of $2-7 .{ }^{4}$

The WHO does not publish estimates for individual countries. Its estimated annual incidence for South America is $3.3 \%$ (3.0\% for Latin America and Caribbean) among women aged 15-44 years. ${ }^{4}$ Thus, our incidence, derived using a direct method, agrees with the WHO value obtained by indirect methods. ${ }^{4}$ The WHO's available sources of data vary among countries but are commonly community surveys and rates of hospital admission because of complications, both of which are adjusted for underreporting. The WHO applies multipliers to admission rates to account for complication rates associated with relevant abortion methods, the proportion of women tending to use hospital care for pregnancy-related conditions, the rate of hospital admissions because of true spontaneous abortion, and other factors. ${ }^{4}$

In our study, factors associated with having an induced abortion were higher age at interview, lower age at first sexual intercourse, geographic region, having children and having multiple sexual partners. One would expect the prevalence to increase with age, and with younger age at first sexual intercourse, owing to increasing exposure to cumulative risk. Of note, we found a high prevalence of induced abortion (7.5\%) among the youngest women in our study (18 years of age) who reported having been sexually active. Lower age at first sexual intercourse was also found by others to be a risk factor for induced abortion. ${ }^{23,24}$ Cross-sectional studies cannot determine causality. However, adolescent women are more likely than older women to have unwanted and unplanned sex and to have poor knowledge of, and access to, effective contraception. ${ }^{25,26}$ For young women, the decision to have an abortion is often influenced by a wish to continue studies or start work, ${ }^{27-29}$ or by the lack of a steady partner to share parenting. ${ }^{30}$

Our finding that having multiple sexual partners was a risk factor for induced abortion was possibly due to a link to contraceptive failure ${ }^{31}$ or to having poor relationships with those partners, ${ }^{24,32}$ both of which could lead to unwanted pregnancies. There may also have been an association between willingness to disclose sensitive behaviours such as having had multiple sexual partners and induced abortion.

The prevalence of induced abortion among women living in cities in the jungle region was 19\%, as compared with $10 \%$ among those in coastal and highland cities. The Peru Demographic and Health Survey also found a higher prevalence in the jungle region. ${ }^{18}$ The reason for this geographic variation is unclear. The respondents in the jungle cities were more likely

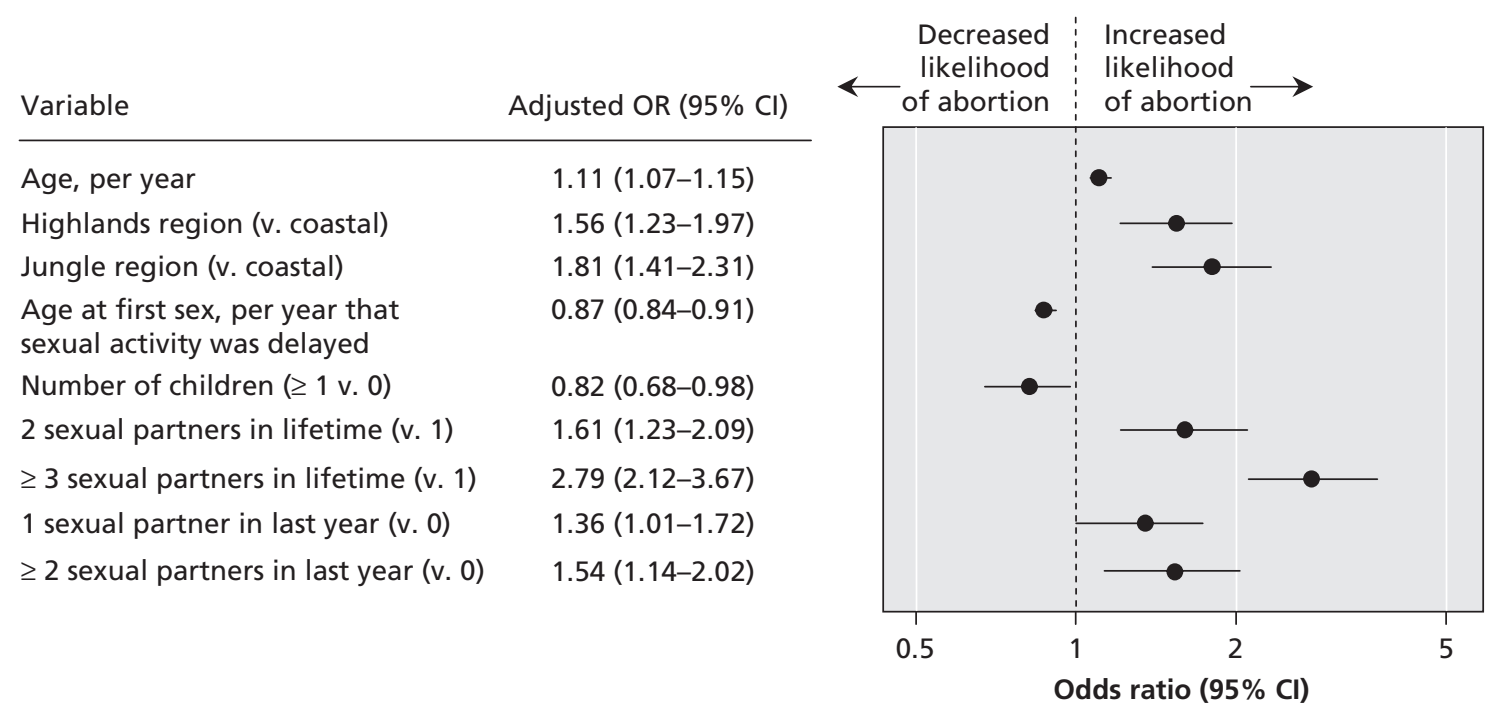

Figure 1: Forest plot of characteristics associated with reporting induced abortion among women reporting ever having been sexually active. An odds ratio (OR) above 1 indicates an increased likelihood of having had an induced abortion. ORs were adjusted by sample strata, primary sampling units and population weights. $\mathrm{Cl}=$ confidence interval. 
than those in the other regions to have been younger at first sexual intercourse and to have had a greater number of sexual partners both in their lifetime and in the year before the survey (data not shown). However, in the multivariable analysis, these risk factors were independent of geographic region.

Women who have induced abortion typically already have children or go on to have them. ${ }^{33}$ In our study, 62.9\% (553/879) of the women who reported having an induced abortion had children, and the others are likely to have them in future.

The lack of an effect of education or income on the prevalence of induced abortion suggests that clandestine induced abortion affects all social groups. It is likely that income level affects the safety of clandestine induced abortion, ${ }^{4}$ but we were unable to explore this topic in the survey.

\section{Limitations}

All studies of induced abortion typically have limitations because of underreporting related to social desirability bias. The problem can be compounded by legal concerns where the procedure is restricted. Often there is underreporting by those involved (as patients or health care workers), an absence of official statistics on abortions, or underreporting of abortionrelated complications in official statistics (owing to individuals not seeking care, or misclassification of induced abortion as spontaneous). ${ }^{2,4}$ We sought to minimize underreporting by using computer-assisted self-administered questionnaires and having well-trained staff conduct interviews in private. ${ }^{34}$ The participation rate of $97 \%$ is reassuring. Also, we asked about the sensitive topic of induced abortion both in the selfadministered questionnaire and in the face-to-face interview, ${ }^{10-12}$ to accommodate individual preferences for disclosure. Nevertheless, there was $91 \%$ agreement in the reporting of abortion (spontaneous, induced or either) between the 2 interview methods.

As with all surveys, another unavoidable cause of underreporting may be recall bias, with older events tending to be reported less frequently than more recent ones. ${ }^{9,35}$ However, we minimized this limitation by focusing on younger adults. As in other studies, such as the one by Jones and Kost, ${ }^{34}$ individual characteristics pertained to the age at interview: we selected women aged 18-29 years so that characteristics would be proximal to the abortion events and the majority of the period at risk would be covered (about $70 \%$ of induced abortions in Latin America occur in women under 30 years ${ }^{4,21}$ ).

\section{Conclusion}

Despite induced abortion being legally restricted in Peru, the estimated incidence of clandestine, potentially unsafe ${ }^{8}$ induced abortion is as high as, or higher than, the estimated incidence in many countries where induced abortion is legal and safe. ${ }^{4}$ The provision of contraception and safer-sex education to women who require them needs to be greatly improved. With almost half of the sexually active women in our study reporting that they do not use contraception, this action alone could greatly reduce the rates of clandestine induced abortion. We hope that our study will contribute to increased awareness of the scale of the problem and political willingness to address it, for which there is public support in Latin America. ${ }^{36}$
This article has been peer reviewed.

Competing interests: None declared.

Contributors: Antonio Bernabé-Ortiz conceived the idea for the paper, performed most of the statistical analysis and prepared the first draft of the manuscript. Peter White contributed to the data analysis and the drafting of the manuscript. Cesar Carcamo designed the survey, sampling procedures and the handheld computer support of the survey; he also contributed to the data analysis. James Hughes contributed to the analysis of the data. Marco Gonzales contributed to the data analysis. Geoff Garnett, Patricia Garcia and King Holmes conceived, designed and supervised the overall study. All of the authors contributed to the revising of the manuscript for important intellectual content and gave their final approval of the version submitted for publication.

Acknowledgement: We acknowledge Wilfredo Evangelista for programming the handheld computer application.

Funding: This study was supported by the Joint International Infectious Disease Initiative of the Wellcome Trust and the Burroughs-Wellcome Foundation (grant no. 059131/Z/99/A), by the University of Washington Center for AIDS Research (grant no. AI 27757), and the Sexually Transmitted Infections and Topical Microbicides Cooperation Research Center by the National Institutes of Health (NIH) Fogarty International Center AIDS International Training and Research Program (grant no. D43-TW00007), by the Comprehensive International Program of Research on AIDS (grant no. 5U19AI053218) and by the Global Health Peru Program at Universidad Peruana Cayetano Heredia, a Fogarty International Center/NIH funded grant (no. 5R25TW007490). Peter White and Geoff Garnett thank the UK Medical Research Council for funding.

\section{REFERENCES}

1. United Nations. 2007. World abortion policies 2007. Department of Economic and Social Affairs. Population Division; 2007. Available: www.un.org/esa/population /publications/2007_Abortion_Policies_Chart/2007_WallChart.pdf (accessed 2008 Apr. 22).

2. Singh S. Hospital admissions resulting from unsafe abortion: estimates from 13 developing countries. Lancet 2006;368:1887-92.

3. Sedgh G, Henshaw S, Singh S, et al. Induced abortion: estimated rates and trends worldwide. Lancet 2007;370:1338-45.

4. Unsafe abortion: global and regional estimates of incidence of unsafe abortion and associated mortality in 2003. Geneva: Department of Reproductive Health and Research, World Health Organization; 2007.

5. Gogna M, Romero M, Ramos S, et al. Abortion in a restrictive legal context: the views of obstetrician-gynaecologists in Buenos Aires, Argentina. Reprod Health Matters 2002;10:128-37.

6. International human rights law and abortion in Latin America. New York (NY): Human Rights Watch; 2005. Available: www.hrw.org/backgrounder/wrd/wrd0106 /wrd0106.pdf (accessed 2008 Apr. 15).

7. Khan KS, Wojdyla D, Say L, et al. WHO analysis of causes of maternal death: a systematic review. Lancet 2006;367:1066-74.

8. Glasier A, Gulmezoglu AM, Schmid GP, et al. Sexual and reproductive health: a matter of life and death. Lancet 2006;368:1595-607.

9. Rossier C. Estimating induced abortion rates: a review. Stud Fam Plann 2003;34: 87-102

10. Fu H, Darroch JE, Henshaw SK, Kolb E. Measuring the extent of abortion underreporting in the 1995 National Survey of Family Growth. Fam Plann Perspect 1998;30:128-33, 138

11. Hasley S. A comparison of computer-based and personal interviews for the gynecologic history update. Obstet Gynecol 1995;85:494-8.

12. Mears M, Coonrod DV, Bay RC, et al. Routine history as compared to audio computer-assisted self-interview for prenatal care history taking. J Reprod Med 2005; 50:701-6.

13. Johnson AM, Mercer CH, Erens B, et al. Sexual behaviour in Britain: partnerships, practices, and HIV risk behaviours. Lancet 2001;358:1835-42.

14. UK Department of Health. Abortion statistics, England and Wales: 2005 (Statistical Bulletin series no. 2006/1). London (UK): The Department; 2006. Available: www.dh .gov.uk/en/Publicationsandstatistics/Publications/PublicationsStatistics/DH_4136852 (accessed 2008 Apr. 22)

15. Abortions by age group [table]. In: Abortions (terminations of pregnancy). Information Services Division, NHS National Services Scotland. Available: www.isdscotland .org/isd/servlet/FileBuffer?namedFile=mat_aas_table7.xls\&pContentDispositionType $=$ inline (accessed 2008 Dec. 26).

16. Finer LB, Henshaw SK. Abortion incidence and services in the United States in 2000. Perspect Sex Reprod Health 2003;35:6-15.

17. Moreau C, Bajos N, Bouyer J; COCON Group. Question comprehension and recall: The reporting of induced abortion in quantitative survey on the general population. Population-E 2004;59:439-54.

18. Demographic and Health Surveys. Peru 2000 Standard DHS. Calverton (MD): 
MEASURE DHS, Macro International; 2000. Available: www.measuredhs.com /countries/country_main.cfm?ctry_id=33 (accessed 2008 Feb. 20).

19. Goldhaber MK, Fireman BH. Re: Estimates of the annual number of clinically recognized pregnancies in the United States, 1981-1991. Am J Epidemiol 2000;152: 287-9.

20. Ferrando D. Clandestine abortion in Peru: facts and figures 2002. Lima, Peru: Centro de la Mujer Peruana Flora Tristan; 2002.

21. Strickler J, Heimburger A. Rodriguez K. Clandestine abortion in Latin America: a clinic profile. Int Fam Plan Perspect 2001;27:34-6.

22. Pan American Health Organization. Health in the Americas. 13th ed. Washington (DC): The Organization; 2002.

23. Cabezas-Garcia E, Langer-Glass A, Alvarez-Vazquez L, et al. Epidemiologic profile of induced abortion [article in Spanish]. Salud Publica Mex 1998;40:265-71.

24. Cheng YM, Wang XY, Lv YH, et al. Study on the risk factors of repeated abortion among unmarried adolescents [article in Spanish]. Zhonghua Liu Xing Bing Xue Za Zhi 2006;27:669-72.

25. Langer A. Unwanted pregnancy: impact on health and society in Latin America and the Caribbean [article in Spanish]. Rev Panam Salud Publica 2002;11:192204.

26. Olinto MT, Moreira-Filho Dde C. Risk factors and predictors of induced abortion: a population-based study [article in Portuguese]. Cad Saude Publica 2006;22:365-75.

27. Finer LB, Frohwirth LF, Dauphinee LA, et al. Reasons U.S. women have abortions: quantitative and qualitative perspectives. Perspect Sex Reprod Health 2005; 37:110-8.

28. Kero A, Hogberg U, Jacobsson L, et al. Legal abortion: a painful necessity. Soc Sci Med 2001;53:1481-90.
29. Tornbom M, Ingelhammar E, Lilja $\mathrm{H}$, et al. Evaluation of stated motives for legal abortion. J Psychosom Obstet Gynaecol 1994;15:27-33.

30. Evans A. The influence of significant others on Australian teenagers' decisions about pregnancy resolution. Fam Plann Perspect 2001;33:224-30.

31. Menezes GM, Aquino EM, da Silva DO. Induced abortion during youth: social inequalities in the outcome of the first pregnancy. Cad Saude Publica 2006;22:1431 46.

32. Barrett G, Peacock J, Victor CR. Are women who have abortions different from those who do not? A secondary analysis of the 1990 national survey of sexual attitudes and lifestyles. Public Health 1998;112:157-63.

33. Misago C, Fonseca W, Correia L, et al. Determinants of abortion among women admitted to hospitals in Fortaleza, North Eastern Brazil. Int J Epidemiol 1998;27: 833-9.

34. Jones RK, Kost K. Underreporting of induced and spontaneous abortion in the United States: an analysis of the 2002 National Survey of Family Growth. Stud Fam Plann 2007;38:187-97.

35. Jagannathan R. Relying on surveys to understand abortion behavior: some cautionary evidence. Am J Public Health 2001;91:1825-31.

36. Yam EA, Dries-Daffner I, Garcia SG. Abortion opinion research in Latin America and the Caribbean: a review of the literature. Stud Fam Plann 2006;37:225-40.

Correspondence to: Dr. Antonio Bernabé-Ortiz, Avenida Honorio Delgado 430, Ingenieria, Lima 31, Peru; 03887@upch.edu.pe 